Autrici:

Annalisa Murgia

Barbara Poggio

Titolo:

Challenging Hegemonic Masculinities. Men's Stories on Gender Culture in Organizations

Anno di pubblicazione:

2009

\title{
Rivista:
}

Organization, vol. 16, Issue 3, pp. 407-423

\section{Codice ISSN:}

1350-5084

doi: $10.1177 / 1350508409102303$

\section{Codici indicizzazione}

Scopus: 2-s2.0-65249156116

Web of Science: 000265211200006

This is a repository copy of "Challenging Hegemonic Masculinities. Men's Stories on Gender

Culture in Organizations"

IRIS Online URL for this paper:

http://hdl.handle.net/2434/594810

Version: Accepted Version

This is the peer reviewed version of the following article:

'Murgia, A and Poggio, B (2009) Challenging Hegemonic Masculinities. Men's Stories on Gender Culture in Organizations. Organization, 16(3), pp. 413-424.

This article may be used for non-commercial purposes in accordance with Wiley Terms and Conditions for Self-Archiving. 


\title{
Challenging Hegemonic Masculinities: Men's Stories on Gender Culture in Organizations
}

\begin{abstract}
The article emphasizes the importance of storytelling in helping or hindering a change in organizational practices brought about by the entry into force of a legislative measure. It concentrates in particular on the introduction of a normative change intended to reshape the dominant gender order by giving fathers the same rights to parental leave as mothers. Whilst storytelling can be an instrument of change, it may also be perceived and used as a means to prevent such change and to consolidate dominant models. In the latter case, analysis of rebellious and marginal voices reveals hegemonic practices and brings out viewpoints silenced by the official versions. The stories of eight men, belonging to different organizations, who have experienced parental leave, enable analysis to be made of the ways in which organizational storytelling can support or prevent the introduction of a change which challenges the symbolic gender order within organizations.
\end{abstract}

Key words. gender order; hegemonic masculinity; storytelling

Storytelling is an important object of (and tool for) the analysis of change within organizations because it allows legitimation or deconstruction, support or obstruction (Boje, 1995; Gabriel, 2000). These considerations certainly apply to changes (and resistance to them) in organizational gender orders and practices, which are often knowable and analysable only if examination is made of stories circulating within organizational settings (Gherardi and Poggio, 2007).

Our aim in this article is to contribute to this strand of analysis by showing that storytelling can be both a tool with which to disseminate alternative practices and an instrument with which to resist change and reinforce dominant symbolic orders. We shall focus in particular on the symbolic gender orders (Gherardi, 1995) conveyed by organizational storytelling, our purpose being to emphasize the difficulty of questioning and challenging it.

Our analysis draws on the fi ndings of previous studies on: (a) the processes by which symbolic gender orders are produced and reproduced in organizations (Gherardi and Poggio, 2007) and (b) the practices by which masculinity is mobilized by men in workplaces (Martin, 2001), highlighting the existence of multiple models of masculinity (Brittan, 1989; Carrigan et al., 1985) and forms of hegemony (Connel, 1987, 1995). In light of these findings we shall concentrate on the narratives furnished by men who have questioned the dominant gender models within the organizations to which they belong.

The article is organized as follows. We first introduce the links between organizational storytelling and gender relationships in order to show how the former contributes to the construction and reproduction of the dominant symbolic gender order. After discussing the context and the methodological implications of our inquiry, we describe the main aspects that emerged from 
interviews with eight men belonging to different organizations. The topic of these interviews was the use of paternity leave, which was introduced in Italy by a law enacted in 2000 but is still uncommon, and strongly resisted by the gender cultures dominant in Italian organizations.

\section{Storytelling, Gender and Organizational Change}

That narratives can yield understanding of organizational phenomena has been increasingly recognized in recent years. Numerous studies have shown that storytelling is a constitutive dimension of organizational action. They have highlighted the various situations in which it occurs and may represent an important resource for the study of organizations. At the origin of this 'narrative turning point' is the belief that analysis of various forms and strategies of storytelling can bring to light how actors interpret and represent their organizations, as well as how they produce shared and intersubjective knowledge of reality (Czarniawska, 1997; Poggio, 2004). Moreover, it is increasingly recognized that narratives are not only organizational artifacts but also tools and processes of organization; they are, it has been said, 'stories that organize' (Czarniawska and Gagliardi, 2003). People in organizations use narrative to make sense of the organizational reality surrounding them, to find a place in that reality, and to craft an organizational self within it. Furthermore, narratives enable researchers to highlight the polyphony of voices present in every organization, and to give voice to silenced stories (Boje, 1995; Brown, 2006).

These considerations apply in particular when attention focuses on the reproduction of gender relations (Hanappi-Egger and Hofmann, 2005). Analysis of story-telling, in fact, uncovers the patterns whereby symbolic gender orders are constructed and reproduced. It shows that the organizational environment is permeated by asymmetrical gender relations (Silberstein, 1988) and by powerful discourses of 'male narrative' concealed by its hegemonic nature (Gherardi and Poggio, 2007).

This article concentrates mainly on the latter aspect, namely the difficulty of challenging the organizational storytelling at the basis of the gender models dominant within organizations. It conceptualizes gender as a dynamic and relational construct. This perspective encourages analysis of what people do, rather than of what they are, in order to show how female characteristics are attributed to women, and masculine ones to men, and 'how 'doing gender' is a social practice which positions people in contexts of asymmetrical power relations' (Bruni et al., 2005: 3). Most studies on the relationship between gender and organization have concentrated on the female experience and on the dynamics by which femininity is constructed. They may have highlighted its diversity from the dominant neutral masculinity, but they have left the latter unexplored. Here, by contrast, we shall focus on the construction of masculinity or, more precisely, of masculinities. There exist a wide variety of masculinity models (Brittan 1989; Carrigan et al., 1985) and they may be practised by both men and women. A concept of particular importance for our purposes here is that of hegemonic masculinity as proposed by Robert Connell. This denotes a configuration of practices 'that occupy the hegemonic position in a given pattern of gender 
relations' (Connell, 1995: 76) in a given setting, and at a particular time. The various forms of masculinity can thus be viewed as being rooted in power relations which can be characterized as either 'hegemonic' or 'subordinate' in relation to each other (Collinson and Hearn, 1994). These masculinities (and femininities) are not static, however, for they are constantly in change.

Specifying the models of hegemonic masculinity, even though they are culturally and historically contingent, yields understanding on how organizations structure in gendered ways the formation and reproduction of social relations, hierarchies and corporate practices (Hearn, 1992). Still useful in this regard is the concept of 'patriarchy', which concerns the hierarchical dimension of relationships not only within the family but also in the broader public context. The processes by which this gender model is constructed and consolidated within organizations have been well described by Joan Acker (1990), who demonstrates how organizational symbols, interactions and hierarchies are constructed on male times, bodies and expectations. Masculinity can therefore be seen as a sub-text: that is, as a set of processes which covertly produce gender distinctions on the basis of asymmetrical power relations which produce consensus or acceptance in regard to the dominant order and hegemonic practices (Benschop and Doorewaard, 1998).

In an article published in 2001, Patricia Yancey Martin sought to show how men mobilize masculinity in workplaces by examining the experiences recounted by their female colleagues. By the term 'masculinity' Martin meant those 'practices that are represented or interpreted by actors and/or observers as masculine within a system of gender relations that gives them meaning as gendered in a masculine way' (Martin, 2001: 588). This attribution takes place on the basis of practices, reference contexts and how it is represented by those occupying positions of power. Martin asserts that masculinity is, for instance, mobilized when several men jointly enact practices to obtain resources, exercise control and differentiate themselves from others and from women - as happens, for instance, in situations of affi liation when men band together for the purpose of mutual support. In this article we shall pay especial attention to the strategies by which the masculinity (or masculinities) can, on the contrary, be created or challenged through the narratives of men who enact unconventional gender practices. We shall focus, in fact, on the stories of men who have taken parental leave for childcare, a task traditionally associated with women, and still rarely undertaken by men in Italy. In this regard, we shall examine how male employees in different organizations responded to an organizational change resulting from recent legislation on the father's right to take parental leave, and how their colleagues and superiors reacted to their requests for such leave. Use of this approach will enable us to understand the role of organizational storytelling in supporting or (more often) obstructing the spread of masculinities that challenge the hegemonic model.

The ability of storytelling to engender change derives firstly from the subjunctive property of narratives, i.e. their capacity to prefigure different scenarios (Bruner, 1990; Good, 1994); secondly, from their power to modify the meanings associated with past and future events (Meyer, 1995); and thirdly, from their capacity to give voice to minorities and persons excluded 
from power (Boje, 1991). Although change can be achieved through the narratives recounted by actors in organizations or transmitted by those organizations (Brown and Humphreys, 2003; Czarniawska, 1997), individual and collective stories may also be used to prevent or obstruct change and to strengthen dominant values and scripts (Martin et al., 1983; Rhodes, 2001). Stories which recount episodes in which the dominant gender order is challenged - as in the present case of exercising the legal right to take leave of absence for childcare - are interesting, firstly because of their disruptive effects and secondly because they may be used to exert control and obtain obedience. In this case, they reinforce dominant practices and values (McConkie and Boss, 1986) in response to stimuli for change deriving from the outside and/or attempts to introduce change from within. Hence stories may also be used as tools with which to unmask hegemonic models and cultures, bringing out the multiplicity of voices within organizations and deconstructing the dominant rhetoric (Boje, 1991, 1995; Fournier, 1998). In particular, they can be used to reveal the existence of different versions of change (Vaara, 2002) and to show how interpretations of change are mutable and negotiable.

\section{Context of Reference and Methodology}

In order to understand whether and how organizational storytelling does or does not support a normative change challenging the dominant gender order, we shall refer to a series of interviews with men who took parental leave for a period of time after the birth of their children, and who therefore had to defy the model of masculinity hegemonic within their work settings. The normative change to which we refer is the introduction of a lawenacted in Italy in 2000 - which entitles fathers to take parental leave following the birth of a child. This law states that during the first eight years of a child's life both parents may abstain from work, even simultaneously, for a period of six months (continuously or piecemeal) up to a maximum of ten months. 1 The main aim of this law is to promote work/life balance policies not addressed - as often happens - exclusively to women, but instead intended to recast the division of labour within the couple and the family. The law thus challenges the symbolic gender order. Its introduction has certainly encouraged the use of paternity leave, although at present the results fall far short of expectations. In 2003 the percentage of male employees in the public sector who took paternity leave was $19 \%$, whilst in the private sector the percentage was much smaller: 3.2\% (Gavio and Lelleri, 2005). The take-up of parental leave in the province of Trento, which was where we conducted our research, has also been rather low: in 2003, $14.8 \%$ of requests for paternity leave were made in the public sector and only $2.1 \%$ in the private sector (Cozza and Poggio, 2005).

In what follows we shall concentrate on eight narrative interviews conducted with men employed in different organizations, both public and private, in a province located in north-eastern Italy. These men recount how they used their legal entitlement to paternal leave, and describe the reactions in their workplaces. The interviews analysed have been selected from a total of eighty conducted in the same province as part of two distinct research projects. The first project addressed gender asymmetries within 
the professional career and the work/life balance. It was based on forty interviews conducted in 2006 with men and women working in the public sector (the provincial administration and the provincial health board). The second project dealt with turning-points in men's and women's working lives, with specific regard to gender and generational differences. In this case, forty interviews were conducted in 2007 with employees in the public sector and commerce, these being the two sectors undergoing the greatest expansion in the province.

The majority of the interviews conducted during these two projects comprised 'mainstream stories'. That is to say, they conformed to the dominant symbolic gender order characterized by an asymmetrical division of roles and tasks between men and women. But the eight stories examined here have been selected because they are to some extent 'eccentric' with respect to the dominant paradigm. In fact, they recount the experiences of men who have challenged the masculinity practices hegemonic within their organizations by exercising their entitlement to parental leave. Both of the research projects just described employed the narrative interview technique, the main purpose of which is to elicit stories concerning the experiences of the interviewees (Riessman, 2008; Wagner and Wodak, 2006). The interviews mainly took place in the workplaces of the interviewees, all of whom were aged between twenty-five and forty-five years old. Each interview lasted for about an hour and a half-with some exceptions, where the range varied from forty minutes to two and a half hours. All the interviews were audio-recorded and transcribed in their entirety. They were then subjected to narrative analysis which examined not only 'what' was related, but also 'how' and 'why' (Riessman, 2008). Hence, account was taken of the fact that no story is ideologically neutral, and that every story legitimates one particular vision of the world and excludes others (Poggio, 2004).

The narrative analysis therefore focused on how change takes place (or has been resisted) in the narratives recounted by organizational actors (Brown and Humphreys, 2003; Czarniawska, 1997) who may either endorse or dispute the dominant scripts (Martin et al., 1983; Rhodes, 2001). In regard to gender, the stories of men who have enacted a form of masculinity different from the hegemonic model have much to tell us about the type of organizational culture in which they are embedded, and on how this is also constructed through discursive practices. Examining discursive practices therefore afford access to the ways in which people actively produce and modify social realities within organizations and in the broader cultural context.

This story has been selected - among the several that could have been narrated - because it highlights alternative or marginal voices often hidden behind the organization's presumed neutrality, uniformity and homogeneity. In our following analysis of the eight experiences recounted by men who had challenged (or tried to do so) the dominant masculinity model, we shall therefore seek to give account of both the symbolic gender order that shapes conversational practices, and the ability of organizational actors to modify (or otherwise) those practices.

We shall use interview extracts to highlight the gender sub-texts transmitted or obstructed by organizational storytelling. To be emphasized is 
that these excerpts are only fragments; hence they cannot be taken as representing the development of the story-line. Nevertheless, they are empirical materials which enable us to illustrate the rhetorics and arguments that organized the narratives dominant or marginal in the organizations examined.

\section{Challenging Hegemonic Masculinity: Men's Stories at Work}

Although the recent Italian law on parental leave concerns both male and female workers, its provisions have been mainly used by women. This can be interpreted as confirming the existence, within organizations, of traditional cultural models uncommitted to the promotion of work/life balance and the reconfiguration of gender roles. Organizational practices in the settings studied were still permeated by a model of hegemonic masculinity constructed around the figure of the male breadwinner - an adult man, head of household, usually working full-time, and with an identity deriving mainly from fulfilment in the public sphere and paid work, and from organizational resources of power and status (Collinson and Hearn, 1994).

In our analysis we identify three principal dimensions of organizational (non-) change. We concentrate first on stories within organizations that communicate the right of male workers to take leave of absence for childcare. We then describe how various masculinities inform managerial practices; but also how management helps reproduce forms of masculinity and dominant power relations. Finally, we concentrate on situations where fathers have been able to assert their right to parental leave without entering into significant conflict with their employer or colleagues. We shall accordingly seek to show how challenging the dominant symbolic gender order alters the hegemonic masculinity model.

\section{Stories That (Do Not) Circulate Within Organizations}

A first salient feature is the recurrence in the interviews of stories describing organizations unaware of the recent law, and in which parental leave for a man had never been discussed - even though more than five years had elapsed since the law had entered into force.

I took leave because I needed to, but also wanted to, when my second daughter was born ... so it was important, one month. All things considered, it was depressing ... To begin with, when I rang the personnel office to find out about the procedure, they didn't know. [Physiotherapist in the Public Health Service]

I discovered that the mayor of *** had given the husband of an acquaintance of mine, also a public-sector worker, permission to stay at home. After that we made all the enquiries, discovery, etcetera, same job grade, same contract, same situation, same everything ... the answer was: 'Oh, well, if the HR manager and his office made a mistake, why shouldn't we?' Nothing. Paternity leave was out of question, because they don't give a damn about the child's rights, they don't even know what they are, that the purpose of parental leave is to protect the child, it's the child's right to have the parents 
close to them, no one considers that. Maybe this law has served to change the situation somewhat, but not for me. [Regional Administration Official]

There's no established routine, I found out that you could take parental leave from a colleague of mine who'd done so; let's say he gave me the push. When I learned that he'd taken parental leave, I said 'Right then, I'll find out about it', so I knew that it was possible. [Sales Sector Employee]

These three extracts from interviews in different organizations, both public and private, show that parental leave for men seems not to have acquired official status. Rather, it enters through the back door, so to speak, through rumours and hearsay, and especially through stories about the first employee fathers to have requested parental leave in a particular workplace or elsewhere. It is not official channels that encourage the (still rare) uptake of opportunities for paternal leave; on the contrary, it is informal storytelling which prompts new fathers to take advantage of the law. The circulation of stories showing that non-standard practices are possible thus creates a first breach in the narrative dominant within organizations. Alternative plots are outlined, and these challenge the stereotype that reconciling work and family is a female issue. At the same time, these stories have a normalizing effect, because they often centre on the difficulties and obstacles encountered by fathers when they decide to request paternity leave and disrupt the order, which must therefore be re-established.

I know male colleagues of mine who've had difficulties in getting permission, so it's still not part of the mindset of our bosses that a father can take leave of absence for long periods. [Regional Tourism Board Employee]

Compared with a woman it's a bit difficult. I mean, I've seen female colleagues ask for two months off in the summer, and they've had no problems in getting it, but when a man asks, they say 'Do you really need it?'. So they're a bit more reluctant. [Local Government Official]

When these men (and those that they talk about in their stories) have asked for paternity leave, even though they are legally entitled to it, they have confounded organizational expectations towards them as employees and, especially, as men (Brandth and Kvande, 2002). The fact that there exists a legal provision which envisages (and even encourages) an entitlement does not mean that organizations will implement it. Regulations are outweighed by well-consolidated practices and cultural models. Stories which propose plots alternative to the dominant ones may be powerful devices with which to induce change in people and workplace cultures (Kaye, 1995). They are therefore perceived as threats and silenced. Moreover, organizational change is not always successful, especially when it opposes the managerial monologue (Aaltio-Marjosola, 1994) through narratives openly in conflict with centrally propagated storylines (Rhodes, 2001; Vaara, 2002).

The dominant organizational culture within the organizations where we conducted our interviews was constructed around narratives aligned with a traditional gender model based on the figure of the male breadwinner. Gender was constructed by a positioning process which attributed different 
characteristics to men and women because they have differently sexed bodies. Consequently, these organizations had a dominant symbolic order of gender which assumed that women are female and men are male, that the former are mostly involved in the private sphere and in (unpaid) care work, and the latter in the public sphere and in paid employment.

The difficulties encountered by male applicants for paternity leave evidence a gender model aligned with the script asserting that functional for the organization (and for the couple) is a sharp division of tasks between men and women characterized by power relations whereby specific forms of masculinity predominate over other possible ones, either masculine or feminine (Alvesson and Billing, 1992; Collinson and Hearn, 1994). Focusing on discursive and relational practices which challenge this model reveals that the presumed neutrality and homogeneity of organizational storytelling often conceal alternative or marginal voices that may destabilize it. In the next section we concentrate on the practices of hegemonic masculinity enacted by managements to exercise gendered power, favouring or inhibiting organizational change.

\section{Hegemonic Masculinity in Managerial Practices}

Organizational storytelling consists of dominant narratives, but also of marginal voices and fragments of narrative (Boje, 1995; Currie and Brown, 2003). The dominant narratives sustain asymmetric relations of power while simultaneously marginalizing some interests in order to privilege others (Humphreys and Brown, 2002). In the case of gender relations, the construct of hegemonic masculinity used by Connell (1987) — in its turn based on the concept of hegemony as a form of ideological domination subtly disguised and taken for granted (Gramsci, 1975) - is useful for identifying masculine hegemonic practices within organizations. The interview excerpts presented here-as well as the larger corpus of materials that we gathered-highlight the importance of management in constructing and legitimizing dominant scenarios. Hegemonic masculinity can thus be analysed as a form of organizational control and power embedded in organizational practices of assessment and interaction. Managers select, reward and promote on the basis of criteria which are apparently gender-neutral (Linstead and Thomas, 2003) but which in fact reflect organizational, overtly-gendered, perceptions of female and male roles. If maternity has always laboured to gain acceptance within organizations, all the more so has paternity. When paternity leaves the private and personal sphere or 'breadwinner' dimension, it becomes a 'spectre' looming over the career chances and life projects of men and women alike.

The fact that I requested paternity leave greatly affected my career. [...]. It's not that they have to mollycoddle you. But they should respect you when you have children, and accept some stress because you switch to part time because you have a small child, or if you take the leave of absence, until it grows up, right? Then when you return you learn much more. The fact that the mother or father can say 'I'm taking leave so I can be with my child', this is respectful towards everybody. But instead you come back to work, you resume your job and you've lost two or three points. Are these family 
policies! There are parents with enormous problems. So we stupidly insist on following a procedure no matter what, because it is not enough to change the law if you can't make use of it. [Municipal Employee]

Clearly when situations like this arise in the ward, they are all very nice, everyone loves you. But in reality you come in, you find there's a wall, because he's managed to stir things up ... we know these situations ... then when I was away for those two months in 2004, for punishment during the three previous months I was only able to work in day surgery, and then I wasn't in the operating theatre for five months, and for us surgeons not operating is a big problem, and when I returned, he wouldn't let me operate any more, so I went to the union, so now he lets me operate one day a week: the minimum. Before I did three or four. With colleagues, yes, we talked about it, but, you know, it's very difficult, after I'd been away for five months, a colleague said to me 'How are you, where've you been? I haven't seen you around, I thought you'd left'. He was the only one that commented, the others no, they all belong to this world. [Surgeon in the Public Health Service]

In these abstracts we can observe that managements regard requests for paternity leave largely as acts of disloyalty to the organization, whose dominant culture is still based on the number of hours spent at work, and on complete availability to the employer (Gherardi and Poggio, 2007). Reducing work commitment in order to concentrate on childcare is a choice obstructed by organizations. It carries a cost in terms of career development: sometimes in the explicit form of censure by the manager, and sometimes in the indirect form of 'flanking work', as one of our interviewees termed it. Managerial practices tend, in fact, to marginalize men who do not adopt (and therefore threaten) the practices of hegemonic masculinity by being 'too' committed to the domestic sphere, to the detriment of their careers.

Our analysis suggests that the imposition of hegemonic masculinity by the male managers described in these stories reproduces the dominance of men who have aligned with this model. Those who oppose it - both men and woman-are less valued, and regarded as less deserving of status and power. Interestingly, such stories circulate regardless of the presence or otherwise of the protagonist - as in the case of the father who returned from parental leave to find 'a wall' erected against him by both his superior and his colleagues. This is once again a story in which an attempt to defy the dominant culture is turned into a social control device with which to prescribe and reinforce managerial actions and values (McConkie and Boss, 1986). It is not by chance that the interviewee said 'they all belong to this world', as if to stress his colleagues' adherence to the dominant organizational culture.

However, hegemonic masculinity is not conveyed solely by narratives about work and the diminished dedication and reliability of a father who decides to take parental leave. It also pervades a more personal sphere. The interviews with men who had taken paternity leave often depicted situations where, besides the halt in their professional careers, management and colleagues questioned their identities as 'fathers' and 'men'. They accused them of 'playing mummy', or even of setting a bad example for their children by deciding to stay at home for a while. 
By now my career has finished in certain respects for this reason. Big problems initially, now smaller ones; however, my chief consultant hasn't spoken to me for two years ... I asked him in July 2003 for leave in November 2003. I chose the month of November amongst other things because it's when nobody goes on holiday. (...) He told me: 'it's a personal affront, don't do it, because it's a bad example to a child if his father stays at home', this I'll always remember, and then he said 'a child must understand that you have to work hard to earn money'. [Surgeon in the Public Health Service]

Then, this stuff, which is a monstrous and absurd swindle, has meant that assuming that equality between the sexes is guaranteed by the Constitution, I got the biggest bum rush at the personnel office of the Region, which refused, just like that, without even discussing the matter, to grant even nursing leave. I did everything, I even went to the ombudsman of the Region, who ticked me off saying 'But if you want to play mummy what's this crap about feeding a child?'. [Regional Administration Official]

When a father remains at home with his child instead of 'working hard to earn money', management accuses him of setting a bad example or dismisses him as a 'he-mummy'. This evinces the presence of specific cultural models which defi ne the gender characteristics that people possess, or must possess, to be considered competent members of a specific culture (Gherardi and Poggio, 2007).

This does not signify, however, that the model of hegemonic masculinity represents a practice applied exclusively by and toward men. For hegemonic masculinity is sustained not only by men, rhetoric and practices but also by the cooperation of men and women.

The approach of the head of personnel at the Region at the time, and she was a woman, was: 'You have to decide: either you have children or you have a career'. Me ... are you recording, it's better you don't record my reply ... because power is like a drug and when you've taken it you can't do without it, in my opinion. [Regional Administration Official]

If I think about the female senior managers who don't have children or have grown-up children, I certainly don't see any big differences from male managers in their treatment of employees, who may have children. It doesn't seem to me that there is any great difference. The attitude probably differs ... from person to person. But between female managers without children and male managers it doesn't seem to me that there is a huge difference, the style seems quite the same to me. [Health Board Employee in the Public Health Service]

These two extracts underline the essential similarity between the reactions of female and male managers to requests for paternal leave by fathers. For that matter, gender studies have for some time disputed the essentialist conception of gender (Butler, 1990; West and Zimmerman, 1987). They underline the existence of a variety of often fragmented and variable masculinities and femininities (Knights and Kerfoot, 2004) and emphasize the practical 
dimension. It is certainly important to highlight the connection that organizational discourses and narratives often establish between masculinity practices and power; but it is also important to avoid the risk of reifying the relationship: masculinity or, more specifically, masculinities are rooted in and generated by interactions, discourses and organizational practices of power, regardless of the sexed nature of bodies.

In the next section we concentrate on the stories of men who have been able to take a period of parental leave without this decisively affecting their careers or their relationships with colleagues and superiors. We shall therefore seek to understand whether and how the introduction of the legal right to paternal leave has disrupted the model of hegemonic masculinity.

\section{Tolerating versus Supporting 'Organizational Change'}

The final salient finding of our analysis emerges from cases where requests for parental leave have apparently been granted without difficulty. These are situations which highlight the persistence of an organizational culture which tolerates change rather than supporting it. Staying at home to look after children is viewed as an extra-ordinary practice - almost as if it were the exception that proves the rule. Consequently of interest are cases in which employers admit that male employees have a right to parental leave, but try to keep it quiet, to prevent rumours circulating about it, so that paternal leave remains an exceptional event rather than a routine one.

In my ward no one took leave, in my hospital yes, a couple of colleagues ... they did it, when school started a year ago. My colleague, his chief consultant told him 'it's your right, I don't agree, don't spread it around. So we'll be friends like before'. For me, though, it was more complicated. [Surgeon in the Public Health Service]

They're obviously happier if ... you take the odd day off, if you're absent one day a week, for the office it's not a problem. Last year I wanted to take a whole month off in August, and when I asked my boss for a month's leave, he asked whether I would only take some days, and guarantee my presence for two days a week, so in the end that's what I did. (...) Yes, I gave in, instead of taking the whole month I took the time off in bits and bobs, guaranteeing my minimal presence in the office. [Local Government Official]

It was therefore the employees themselves who described this experience as a rarity, a privilege granted by the organization which is somehow 'adapted' to the dominant culture based on an organizational model which rewards physical presence in the workplace. These examples illustrate the complexity of gender cultures in workplaces. The narrators in these cases were victims of the hegemonic masculinity model because they had not been able fully to exercise their rights to parental leave. But they were also co-producers of the selfsame masculinity model that penalized them, because they had not challenged either the management of organizational time or the distribution of workloads during their absence.

Other stories instead accentuated the dimensions of emergency and nonchoice. Parental leave in these cases was requested (and tolerated by the 
organization) in order to deal with situations in which the mother could not care for the children or could not do so on her own.

When they found out that there were two children, they showed, my boss most of all, great understanding about my leave, absences, so many things. Erm, for instance he had no problem in letting me work a bit extra on the other days of the week, and then make up the hours on Friday, so that I could be at home. With some time off in lieu, I could work half-day on Fridays and be at home and avoid a journey, working a bit extra on the other days of the week. [Local Government Official]

Formally, I had to ask for one month because it was the minimum amount, but in fact I took fifteen days off for the second daughter. Then when it's been necessary, I've used my sick leave entitlements to look after the children; when my wife had work commitments, I looked after them when she couldn't. [Health Board Employee in the Public Health Service]

These interview extracts illustrate a positioning 'alternative' to the gender model in the organizations where we conducted our research. This positioning contributes to progressive organizational change by supporting implementation of the law on parental leave. Nevertheless, taking such leave does not automatically mean challenging hegemonic masculinity. Even if a male employee's exercise of his entitlement is at odds with an organizational culture which requires employees to leave their private lives outside the office door, this does not necessarily imply a distancing from the organization, nor the construction of 'rebellious' stories alternative to the hegemonic narrative. It may be that - as in the above cases - these are temporary and very brief episodes created by particular events (expected or unexpected) and that 'normality' is re-established when the emergency has subsided.

It is thus evident how difficult it is to propose alternative solutions without conflicting with the narrative imposed by the organization. Organizational change, like 'organizational non-change' (when the law on paternal leave is not applied), can be negotiated by mutual consent, but it can also be imposed without necessarily being disputed.

Observation of discordant and opposing voices, of how they situate themselves and contribute to organizational storytelling, has enabled us to understand the processes by which dominant symbolic gender orders are re-constructed, and to show how power relations are permeated by practices of hegemonic masculinity which exacerbate the subjugation of organizational members to the dominant culture. Organizational change is not transmitted solely by dominant narratives; also marginal actors play their part, because individuals are involved in asymmetric power relations (Clegg, 1981). People do not simply follow the dominant cultural models. They enact practices that adapt those models to themselves; but they may also resist them, sometimes going beyond the organizational culture and the hegemonic gender order to do so. Listening to marginal and peripheral voices therefore requires us to emphasize the emergence, even if with some diffi culty, of alternative narratives within organizations. 


\section{Final Remarks}

The aim of this study has been to contribute to the debate on storytelling and organizational change by directing attention to the ways in which narratives may help or hinder the introduction of a change which threatens the symbolic gender order dominant in organizations.

We have first shown that marginal stories are important devices with which to convey organizational change (Kaye, 1995) and that they are able to disrupt the managerial model and the dominant organizational narratives (Aaltio-Marjosola, 1994; Rhodes, 2001). We have examined the voices of organizational actors who related stories discordant with the narratives conventional in their organizations, according to which fathers do not stay at home to care for children, despite the attempt by the law to encourage this practice. Analysis of the interviews has shown that when men take parental leave, organizations are inclined to consider them exceptional cases, trying to reduce their significance and visibility. In addition, our analysis has demonstrated that cultural practices are able to counterbalance, or at least to restrict, the effect of regulatory changes.

Secondly, we have shown the capacity of managements to reproduce the dominant narratives on which asymmetrical relationships are based within organizations (Humphreys and Brown, 2002). We have concentrated in particular on the ways in which managers, whether men or women, can contribute to maintenance of the hegemonic masculinity model by marginalizing other forms of masculinity and femininity (Collinson and Hearn, 1994; Martin, 1996).

Our study intends to contribute to the debate on organizational storytelling by highlighting the complexity and ambivalence distinctive of change processes in organizational symbolic gender orders, and the important role of storytelling in those processes. Interestingly, our male interviewees contributed, even unwittingly, to the maintenance of the symbolic order of which they depicted themselves as the victims. On the one hand, the stories recounted seemingly centred on attempts by these fathers to change existing practices and to use a right denied them by the organization. On the other hand, when the story became more detailed, and described how such practices were concretely implemented, it showed how a form of remedial work (Gherardi, 1995) repaired the breach and re-established the dominant order (Bruner, 1990).

Our study has obviously been restricted in its scope. It could now be developed with further empirical inquiry which flanks analysis of dominant narratives with consideration of marginal voices. The purpose would be to identify the diverse masculinities and femininities within organization and the power relations in which they are embedded. Also suggested is further examination of the complex relationship between normative changes and gender practices, highlighting the ambiguities and contradictions which characterize them. 


\section{Notes}

1. Before this law came into effect, a father could take leave of absence only during the first year of the child's life, and only if the mother was a dependent employee who had renounced her own right to maternity leave. The new regulation ratifies a change from protecting women to encouraging care-work by both parents.

\section{References}

Aaltio-Marjosola, Iiris (1994) 'From a "Grand Story" to Multiple Narratives: Studying an Organizational Change Project', Journal of Organizational Change Management 7: $56-67$.

Acker, Joan (1990) 'Hierarchies, Jobs, Bodies: A Theory of Gendered Organizations', Gender and Society 4(2): 139-58.

Alvesson, Mats and Billing, Yvonne Due (1992) 'Gender and Organization: Toward a Differentiated Understanding', Organization Studies 13(2): 73-106.

Benschop, Yvonne and Dooreward, Hans (1998) 'Covered by Equality: The Gender Subtext of Organizations', Organization Studies 19(5): 787-805.

Boje, David M. (1991) 'The Storytelling Organization: A Study of Story Performance in an Office-Supply Firm', Administrative Science Quarterly 36: 106-26.

Boje, David M. (1995) 'Stories of the Storytelling Organization: A Postmodern Analysis of Disney as "Tamara-land"', Academy of Management Journal 38(4): 997-1035.

Brandth, Berit and Kvande, Elin (2002) 'Reflexive Fathers: Negotiating Parental Leave and Working Life', Gender, Work and Organization 9(2): 186-203.

Brittan, Arthur (1989) Masculinity and Power. Oxford: Blackwell.

Brown, Andrew D. (2006) 'A Narrative Approach to Collective Identity', Journal of Management Studies 43(4): 731-53.

Brown, Andrew D. and Humphreys, Michael (2003) 'Epic and Tragic Tales: Making Sense of Change', Journal of Applied Behavioral Science 39(2): 121-44.

Bruner, Jerome S. (1990) Acts of Meaning. Cambridge, MA: Harvard University Press.

Bruni, Attila, Gherardi, Silvia and Poggio, Barbara (2005) Gender and Entrepreneurship. An Ethnographic Approach. London: Routledge.

Butler, Judith (1990) Gender Trouble: Feminism and the Subversion of Identity. New York, NY: Routledge.

Carrigan, Tim, Connell, Robert W. and Lee, John (1985) 'Toward a New Sociology of Masculinity', Theory and Society 14(5): 551-603.

Clegg, Stewart M. (1981) 'Organizations and Control', Administrative Science Quarterly 26: 545-62.

Collinson, David L. and Hearn, Jeff (1994) 'Naming Men as Men: Implications for Work, Organization and Management', Gender, Work and Organization 1(1): 2-22.

Connell, Robert (1987) Gender and Power. Cambridge: Polity Press.

Connell, Robert (1995) Masculinities. Berkeley, CA: University of California Press.

Cozza, Michela and Poggio, Barbara (2005) L'uso dei congedi parentali nella Provincia di Trento. Trento: Dipartimento di Sociologia e Ricerca Sociale.

Currie, Graeme and Brown, Andrew D. (2003) 'A Narratological Approach to Understanding Processes of Organizing in a UK Hospital', Human Relations 56(5): 563-86.

Czarniawska, Barbara (1997) A Narrative Approach to Organization Studies. London: Sage. 
Czarniawska, Barbara and Gagliardi, Pasquale (2003) Narratives We Organize By. Amsterdam: John Benjamins.

Fournier, Valérie (1998) 'Stories of Development and Exploitation: Militant Voices in an Enterprise Culture', Organization 5(1): 55-80.

Gabriel, Yiannis (2000) Storytelling in Organizations. New York, NY: Oxford University Press.

Gavio, Francesca and Lelleri, Raffaele (2005) La fruizione dei congedi parentali in Italia nella pubblica amministrazione, nel settore privato e nel terzo settore. Roma: Osservatorio sulla famiglia.

Gherardi, Silvia (1995) Gender, Symbolism and Organizational Cultures. London: Sage.

Gherardi, Silvia and Poggio, Barbara (2007) Gendertelling in Organizations: Narratives from Male-dominated Environments. Stockholm: Liber AB.

Good, Byron J. (1994) Medicine, Rationality, and Experience: An Anthropological Perspective. London: Cambridge University Press.

Gramsci, Antonio (1975) Quaderni del carcere, Edizione critica dell'Istituto Gramsci a cura di V. Gerratana. Torino: Einaudi.

Hanappi-Egger, Edeltraud and Hofmann, Roswitha (2005) 'Narratives, Gender and Organizations' in G. Scheryögg and J. Koch (eds) Knowledge Management and Narratives. Organizational Effectiveness Through Storytelling, pp. 215-28. Berlin: Erich Schmidt Verlag.

Hearn, Jeff (1992) Men in the Public Eye: The Construction and Deconstruction of Public Men and Public Patriarchies. London: Routledge.

Humphreys, Michael and Brown, Andrew D. (2002) 'Narratives of Organizational Identity and Identification: A Case Study of Hegemony and Resistance', Organization Studies 23: 421-47.

Kaye, Michael (1995) 'Organisational Myths as Storytelling as Communication Management: A Conceptual Framework for Learning as Organisation's Culture', Journal of the Australian and New Zealand Academy of Management 1(2): 1-13.

Knights, David and Kerfoot, Deborah (2004) 'Between Representations and Subjectivity: Gender Binaries and the Politics of Organizational Transformation', Gender, Work and Organization 11(4): 430-54.

Linstead, Alison and Thomas, Robyn (2003) "“What Do You Want From Me?” A Poststructuralist Feminist Reading of Middle Managers' Identities', Culture and Organization 8(1): 1-20.

Martin, Joanne, Feldman, Martha S., Hatch, Mary Jo and Sitkin, Sim B. (1983) 'The Uniqueness Paradox in Organizational Stories', Administrative Science Quarterly 28: $438-53$.

Martin, Patricia Yancey (2001) “" Mobilizing Masculinities”: Women's Experiences of Men at Work', Organization 8: 587-618.

Martin, Patricia Yancey (1996) 'Gendering and Evaluating Dynamics: Men, Masculinities, and Managements', in D. Collinson and J. Hearn (eds) Men as Managers, Managers as Men, pp. 186-209. London: Sage.

McConkie, Mark L. and Boss, R. Wayne (1986) 'Organizational Stories: One Means of Moving the Informal Organization During Change Efforts', Public Administration Quarterly 10(2): 189-206.

Meyer, John C. (1995) 'Tell Me a Story: Eliciting Organizational Values from Narratives', Communication Quarterly 43(2): 210-24.

Poggio, Barbara (2004) Mi racconti una storia? Il metodo narrativo nelle scienze sociali. Roma: Carocci. 
Rhodes, Carl (2001) Writing Organization: (Re)presentation and Control in Narratives at Work. Amsterdam: John Benjamins.

Riessman, Catherine Kohler (2008) Narrative Methods for the Human Sciences. Thousand Oaks, CA: Sage.

Silberstein, Sandra (1988) 'Ideology as Process: Gender Ideology in Courtship Narratives', in A. D. Todd and S. Fischer (eds) Gender and Discourse: The Power of Talk, pp. 125-49. Norwood, NJ: Ablex.

Vaara, Eero (2002) 'On the Discursive Construction of Success/Failure in Narratives of Post-Merger Integration', Organization Studies 23(2): 213-50.

Wagner, Ina and Wodak, Ruth (2006) 'Performing Success: Identifying Strategies of Selfpresentation in Women's Biographical Narratives', Discourse and Society 17(3): 385-411.

West, Candace and Zimmerman, Don H. (1987) 'Doing Gender', Gender and Society 1(2): 125-52. 